\title{
The Value and Design Strategy of Traditional Farming Culture Inheritance
}

\author{
Hua Long ${ }^{1}$, Bo Yang ${ }^{2}$, Binbin Sang ${ }^{3}$ \\ ${ }^{1}$ College of Agronomy and Biotechnology, Yunnan Agricultural University, Yunnan, Kunming 650201, \\ ${ }^{2}$ Department of foreign languages, Kunming Medical University, Yunnan, Kunming, 650500, \\ ${ }^{3}$ Vocational and Technical Education College of Yunnan Normal University, Yunnan Kunming, 650092
}

Keywords: farming culture; inheritance; value concept

\begin{abstract}
Agricultural culture is the crystallization of the wisdom of the Chinese people for thousands of years. It is not only the material basis for the Chinese nation to propagate from generation to generation with life and growth in nature, but also affects the values and ethics of generations. Inheriting the traditional farming culture of the Chinese nation is conducive to realizing and stabilizing the sustainable development of our country. It is of great significance to study and carry forward the traditional excellent agricultural culture in China especially in the period of social transformation in our country, under the current situation of the destruction of the ecological environment, the lack of national morality and subversion of values.
\end{abstract}

\section{The connotation of farming culture}

The long-term residence and happiness has precipitated the infinite wisdom of life and explored the balance between exerting people's subjective initiative and respecting the laws of nature. At the same time, the demand for manpower in agricultural production has strengthened the awareness of peasants to breed and progeny, and formed a culture of filial piety and fraternal duty, providing for the aged and keeping children with life and growth in nature. The culture of filial piety and fraternal duty is the ethical foundation of ancient society. The culture of family filial piety and fraternal duty has formed the faithfulness to monarch through the transformation of Confucianism. The loyalty and filial piety culture has established a close bond between people and enhanced the cohesiveness of the nation. This is also an important reason why the Chinese nation has survived countless times and survived.

\section{The inheritance value of farming culture}

The transformation of agriculture. China is in a critical period of social transformation. The rural population is becoming less and less. The reduction of rural population puts forward requirements for agricultural modernization. It is necessary to guarantee agricultural production and supply on the premise of reducing rural population. The number of peasants is becoming less and less in the process of modernization. It is necessary to cultivate excellent new farmers in order to guarantee the development of agriculture.

The transformation of ideas. People's spiritual life has suffered a huge crisis in the process of modernization in the West. China must learn from the Western experience and explore the cultural development path with Chinese characteristics. Therefore, the construction of spiritual culture in our country must inherit and utilize the excellent resources critically contained in traditional culture, especially the contents that reflect the common ethics of human beings. Farming culture is a rich culture of China's development for thousands of years. The critical inheritance and development for it is conducive to the steady transformation of our society.

Industrial society is different from agricultural society. Industrial society ignores individual differences and pays attention to industrial production efficiency. Natural people with rich personalities are "screwed". At the same time, people often feel more exhausted and empty after a game of entertainment with urban life in fast-paced and prevalent entertainment culture. People's 
thinking lacks depth and their thinking is limited in this cultural context. The farming culture was born in the local folk and coexisted with the general public. It has a strong humanistic color and contains excellent cultural thoughts such as Confucianism and Taoism. Confucianism also pays attention to group harmony, but does not neglect individual values. This kind of thinking that takes into individuals and groups account is a good medicine to solve the anxiety of industrialized individuals. Confucianism values people's "sincerity" and requires people to have "shame" and emphasize individual self-cultivation. Let people cultivate themselves from the inside out, so as to achieve the realm of living and working.

The urbanization process has a profound impact on rural lifestyles and cultural traditions. Rural traditional culture, good customs and value systems have been impacted and collapsed in the process of urbanization, due to the strong cultural strength of the metropolis, which causing people to lose their original values or enlarge some bad values in real life, At the same time, the modern cultural function of the individual fails to develop in time and fully because the level of rural education lags behind the city. The peasants and rural areas are more difficult to resist the dross and temptation of urban culture, and it is easier to absorb the part of the decline and decay.

\section{The design strategy of inheritance of farming culture}

The farming civilization is undergoing a fundamental shake-up due to changes in the social environment, and some cultural heritages are or have disappeared from us quietly. More than 400,000 villages have disappeared in rural China in the past 30 years. Countless precious agricultural cultural resources have disappeared and traces are hard to find with traditional houses and historical blocks being demolished ruthlessly. It is urgent to strengthen the rescue and protection of China's rich and colorful agricultural cultural heritage.

Farming culture is the essence of Chinese national culture and the key factor for the prosperity of our nation. Young people have an important obligation to inherit and carry forward the traditional culture of the Chinese nation as a future builder of our country. Therefore, it is necessary to incorporate farming culture into the teaching system, let the farming culture enter the book and enter the classroom, so that the majority of young people can understand the traditional farming culture of our country. In addition, we must also pay attention to the actual participation of young people in agricultural production activities.

Promoting urban agriculture should be carried out in the following two directions. First, develop industrial agriculture in large-scale production in urban suburbs actively to ensure the food supply of the city; Second, encourage the development of small and medium-sized leisure agriculture and traditional agriculture from the perspective of inheritance of farming culture. The government needs to formulate various protection measures, improve agricultural related laws, and formulate an agricultural management system insurance system in order to ensure the healthy and comprehensive development of urban agriculture. It is necessary to improve agricultural ecological norms, promote agricultural science and technology innovation and promotion, and improve the circulation of agricultural products for production-oriented agriculture.

\section{Summary}

It is imperative to learn the Chinese culture of farming culture and inherit the tradition of farming culture under the current crisis of China's environment and the general situation of people's spiritual emptiness, reversed values, and moral loss. General Secretary Xi Jinping pointed out that "farming culture is a valuable asset of China's agriculture and an important part of Chinese culture. It must not be lost, and must be carried forward continuously." Inheriting the Chinese nation's farming culture should focus on protecting relevant cultural heritage, paying attention to the continuation of excellent cultural thoughts, focusing on innovation and building a new era of farming culture, so as to realize the development of the Chinese nation's farming culture truly and ensure the sustainable development of China. 


\section{References}

[1] Peng Jinshan. The Connotation of Farming Culture and Its Significance to Modern Agriculture [J]. Northwest Ethnic Studies. 2011(01).

[2] Hu Guangwei. Modern Interpretation of Farming Culture-Agricultural Culture and Socialist New Countryside Construction [J]. Chinese Culture Forum .2009(S2).

[3] Xia Xuejun. Inheritance Value and Path Exploration of Farming Culture [J]. China Township Enterprises .2012(12).

[4] Li Shumei. The special way of social transformation in China and the development of human beings [J]. Social Science Front. 2005(03).

[5] Zong Jinyao. Promoting Farming Culture and Expanding Agricultural Multi-functionality [J]. Heilongjiang Food. 2015(12). 